\title{
Fewer library staff and more volunteers or vice versa? Staffing in Ontario hospital libraries and volunteer use
}

\author{
Mary McDiarmid and Ethel W. Auster
}

\begin{abstract}
During times of fiscal restraint, many hospitals are questioning library budgets. As a result, hospital library managers are faced with justifying their current levels of staffing. Increases in a library's staffing complement are even harder to realize. The purpose of our research was to learn more about the extent of volunteer use in hospital libraries and to increase our understanding of the issues and challenges related to using volunteers. The target population of the research was managers of Ontario hospital libraries. To identify potential respondents, the membership listings for the Canadian Health Libraries Association and Ontario Hospital Libraries Association were consulted. DOCLINE ${ }^{\circledR}$ yielded additional names of library managers. In April 2003, a mail survey questionnaire was sent to 89 Ontario hospital library managers. Findings relating to staffing issues in Ontario hospital libraries are discussed with particular reference to two key factors: the extent of volunteer use and the adequacy of staffing. This research has highlighted a number of implications for practice, including the need for (1) prescriptive staffing standards and formalized volunteer-use policies; (2) advocacy, lobbying, and networking with other components of the health care system; and (3) formalizing staffing planning in hospital libraries to ensure they are staffed with appropriate personnel.
\end{abstract}

\section{Introduction}

Few hospital library managers have not gone to the administrators of their hospitals with a request for additional staffing. More often than not, their request is denied because of funding shortfalls, or because other departments involved more directly in patient care are given priority over the library for funds and staffing. Volunteers have been a valuable resource for all types of libraries for many years. Important issues have arisen, compelling library managers to reconsider whether and how volunteers should be used in their libraries. One of these issues is the use of volunteers to replace staff lost to budget cuts. The use of volunteers in a hospital library can be a make-or-break decision with respect to acquiring and retaining adequate staffing in an Ontario hospital library. On the one hand, a hospital librarian in Ontario has a ready supply of volunteer workers available through the hospital's auxiliary program who may be used to help out in the library when workloads are heavy and staffing is inadequate. On the other hand, given the depressed economic situation, a hospital librarian may willingly or unwillingly (because of administrative pressures) use volunteers in lieu of paid staff to provide services, and there is a real risk that jobs can be lost, or new paid positions cannot be justified. For example, in 1996, a Canadian hospital librarian found herself out of a job and replaced by a volun-

M. McDiarmid ${ }^{1}$ and E.W. Auster. Faculty of Information Studies, University of Toronto, 140 St. George Street, Toronto, ON M5S 3G6, Canada.

${ }^{1}$ Corresponding author (e-mail: seajay@interlinks.net). teer who was a retired librarian (J. Kublin, personal communication, 1996). In September 2002, because of budget cuts, another librarian's position was eliminated at a hospital in Toronto, and the library volunteers continued to work in the library with one of them coordinating the library services (T. Zarrin, personal communication, 2002). These examples, by no means unique, illustrate the controversial way that volunteers can be used in hospital libraries.

A lack of formal policies regarding volunteer use and prescriptive standards regarding the staffing of hospital libraries are part of the problem. Neither the Canadian Health Libraries Association / Association des bibliothèques de la santé du Canada (CHLA / ABSC), a group that represents over 400 individuals in the health sciences library field in Canada, nor the Canadian Library Association has a formal position statement on the use of volunteers in libraries (P. Ellis and L. Scott, interview, 2001; V. Whitmell, personal communication, 2001). The American Medical Library Association does not have an official policy on using volunteers in hospital libraries (C.J. Funk, personal communication, 2003). Some library associations have recognized the volunteer issue and have drafted policies or guidelines on their use. The American Library Association's Guidelines for Using Volunteers in Libraries states, "If it is essential that a minimum or basic library program be initiated or developed by volunteers, this use of voluntary persons should be considered as a temporary measure pending the employment of staff and that volunteers should not supplant or displace established staff positions" [1]. The Library Association of Great Britain is opposed to the introduction of voluntary labour to compensate for the reduction or withdrawal 
of services caused by redundancies, non-filling of vacant posts, or inadequate staffing of establishments [2]. The current recommended standards for Canadian health care facilities specify that "library and information services [are] managed by a qualified librarian, and there are adequate professional, technical, and clerical staff to meet the needs of clients and the stated goals and objectives of the service" [3]. Unfortunately the standards do not define what "adequate" entails. The standards recommend that "where the needs of the library's clients do not warrant the services of a librarian on a full-time basis, access to a library be made available through either a library consultant, circuit or outreach librarian, or a joint venture, multi-facility arrangement and that the day-to-day duties of the library may be accomplished by a qualified library technician or an employee with specific training in library techniques" [3]. The problem with this statement is that it is left unclear who decides when the library's clients do not warrant the services of a librarian. In practice, the CHLA / ABSC standards are for guidance only, and Canadian hospitals are not legally or otherwise required to follow them to gain accreditation from the Canadian Council on Health Services Accreditation (CCHSA). The CCHSA categorizes Canadian hospital libraries under the "information management practices" section, and there are no prescribed standards regarding staffing of the hospital library. Not only are there no staffing requirements specified in the accreditation manual, there is also no requirement that a Canadian hospital has a library. Hospitals are required under standard 5.0 to ensure that "there are processes to provide data and information in print or electronic format", but how this is accomplished is left to the discretion of each hospital's administration [4]. A hospital administrator could claim that he or she fulfils this accreditation requirement by having an Internet connection and access to online medical databases.

This study was undertaken to develop a picture of how volunteers are used in hospital libraries and to describe the attitudes hospital library managers hold regarding the use of volunteers. Staffing issues in Ontario hospital libraries are discussed with particular reference to two key factors: the extent of volunteer use in the hospital libraries and the adequacy of staffing in the libraries.

\section{Methods}

\section{Design}

Survey research was chosen as the methodology because it is appropriate for descriptive studies of large populations. A self-administered mail questionnaire was used for economy and speed. Both quantitative and qualitative data were gathered through a mail survey questionnaire that included close- and open-ended questions. The most significant advantages of mail questionnaires were that the questionnaires could be sent to a study population that was dispersed over a wide geographical area and it could be answered by respondents at their own convenience.

\section{Survey instrument}

An eight-page questionnaire survey instrument was used. The questionnaire and accompanying literature were designed according to Dillman's Total Design Method because it has proven to be an effective way of improving the response rates for mail surveys [5]. This study confirmed the effectiveness of the Total Design Method, as a 92\% response rate was achieved. The administration of the survey followed Salant and Dillman's four-step process for mail survey questionnaires [6]. A pretest of the questionnaire was done before the definitive study. A pretest questionnaire was given to six volunteers who were known to the researcher and worked in health sciences libraries that were similar to the study population. These pretest participants completed the survey and reviewed it for content validity. Changes suggested in the pretest were incorporated into the final survey form.

\section{Survey distribution}

To identify hospital library managers, the membership listings for the CHLA / ABSC and the Ontario Hospital Libraries Association were consulted. DOCLINE ${ }^{\circledR}$ yielded additional names of library managers. This produced a mailing list of 89 library managers. This research was not restricted to librarians, that is, those holding a master's degree in library science (M.L.S.), since it was expected that library managers in many of the smaller hospitals would not be librarians. Managers from psychiatric hospitals and addiction research libraries were excluded because, in their facilities, they do not have access to volunteers that are equivalent to general hospital volunteers. Hospitals without staffed libraries were excluded because they do not have a paid staff member who manages the library. Of the 80 questionnaires returned, all but 1 were usable for analysis. SPSS version 11.5 for Windows (SPSS Inc., Chicago, Ill.) was used to analyze the data.

\section{Findings}

\section{Extent of volunteer use}

Sixty-five percent of Ontario hospital libraries currently use volunteers and $35 \%$ of libraries (28) do not use them. Of the 28 hospital libraries not currently using volunteers, 20 had used them in the past, and 8 libraries reported having never used volunteers in the library. In total, there were 119 volunteers used in Ontario hospital libraries. The largest number of volunteers used in a single hospital library was 45. Forty-seven per cent of the libraries that used volunteers, reported using only one volunteer. Twenty percent of the libraries used 5 or more volunteers; $18 \%$ used 2 volunteers in the library. An equal number of libraries, 4 (8\%), reported using either 3 or 4 volunteers in the library. Volunteers contributed a total of 728 working hours per week. The number of hours worked ranged from 1 to $110 \mathrm{~h}$ per week. The mean number of hours worked by volunteers per week was $14.6 \mathrm{~h}$. However, because the mean is affected by the extreme values in the range, i.e., 1 and 110, the inter-quartile range is a more meaningful description of the average numbers of hours worked by volunteers per week. The inter-quartile range is $11.6 \mathrm{~h}$ per week.

\section{Staffing in the libraries}

Respondents were asked to describe the staffing situation in their library by indicating the number and type of paid positions in the library. Respondents were then asked to indi- 
Table 1. Library positions and volunteer use $(n=79)$.

\begin{tabular}{|c|c|c|c|c|c|c|}
\hline \multirow[b]{2}{*}{ Library position } & \multicolumn{2}{|c|}{$\begin{array}{l}\text { Libraries using } \\
\text { volunteers }\end{array}$} & \multicolumn{2}{|c|}{$\begin{array}{l}\text { Libraries not currently } \\
\text { using volunteers }\end{array}$} & \multicolumn{2}{|c|}{ Total no. of positions } \\
\hline & Full-time & Part-time & Full-time & Part-time & Full-time & Part-time \\
\hline Librarians & 36 & 9 & 32 & 6 & 68 & 15 \\
\hline Library technicians & 41 & 3 & 34 & 5 & 75 & 8 \\
\hline Assistants or clerks & 8 & 1 & 10 & 5 & 18 & 6 \\
\hline Other positions & 2 & - & 1 & 2 & 3 & 2 \\
\hline Total & 87 & 13 & 77 & 18 & 164 & 31 \\
\hline
\end{tabular}

cate "yes" or "no" to three questions posed to discover whether the library manager believed the library was adequately staffed, whether the library had experienced a reduction in staff in the past 5 years, and whether the library staff was unionized.

\section{Number and type of paid positions in the library}

Respondents were provided with a list of positions and asked to indicate how many paid employees occupy each type of position in their library. The positions were librarian, library technician, library assistant or clerk, and other. The "other" category was provided so respondents could describe other staff positions present in the library.

Respondent libraries $(n=79)$ were staffed with a total of 195 paid positions. Of the 195 paid positions, $164(84 \%)$ were full-time jobs, and 31 positions (16\%) were part-time. Librarians, those with an M.L.S. or equivalent degree, held $83(43 \%)$ of the total paid positions and $68(41 \%)$ of the full-time positions. Library technicians held 83 (43\%) of the paid positions and $75(46 \%)$ of the full-time positions. Library assistants or clerks filled $24(12 \%)$ of the total paid positions and $18(11 \%)$ of the full-time positions.

A $\chi^{2}$ test was performed to assess whether employment status was associated with the use of volunteers in the library, but no evidence of such a relationship was found. The number of paid positions in libraries using and not using volunteers arranged by library position and job status is summarized in Table 1.

Five respondents identified their roles as "other" positions. The full-time positions in the "other" job title category included two library managers who described their role as administrative assistant and health records technician, respectively, and one respondent who reported having a "B.A. in some other field but had taken some library course work". The remaining two part-time library managers consisted of a secretary and a "manager" of an unspecified department. Not included in Table 1 are the responses of two respondents that selected the "other" category but did not specify whether they were full- or part-time employees. They noted elsewhere on the questionnaire that they were employed as full-time health records technicians, but they did not receive any compensation for the library duties and performed library work on an as-needed basis.

\section{Adequacy of staffing}

There is evidence of an association between a manager's belief in the adequacy of staffing in the library and the use of volunteers. Specifically, volunteers were more likely to be used by managers who did not believe they were adequately staffed $\left(\chi^{2}(1, n=76)=4.11, p=0.043\right)$. Fifty-eight percent of managers did not believe that their libraries were adequately staffed with paid employees. Library managers currently using volunteers held opposing views on this question with $16(33 \%)$ indicating they were adequately staffed and twice as many, $32(67 \%)$, reporting they were not adequately staffed. Conversely, 16 (57\%) managers not using volunteers believed they were adequately staffed and $12(43 \%)$ of non-users did not believe so. In total, $36(71 \%)$ managers using volunteers believed that the presence of volunteers did not hinder their ability to increase their paid staffing complement. Nine (18\%) managers using volunteers believed the presence of volunteers acted as a barrier to increasing the library's staff complement.

Library managers' responses to the question of whether they believed their libraries were adequately staffed with paid employees are summarized in Table 2.

\section{Staff reductions}

Most library managers (52) representing $69 \%$ of the total responses $(n=75)$, did not experience a reduction in library staffing in the past 5 years, while $23(31 \%)$ reported that their staffing had been reduced. Respondents who did not have a reduction in staffing in the past 5 years included 34 (45\%) managers from libraries using volunteers and 18 (24\%) from libraries with no volunteers. Of those respondents who reported a staffing reduction, $13(17 \%)$ were from libraries currently using volunteers and 10 (13\%) represented libraries not using volunteers. Four respondents did not answer this question.

Table 3 shows the responses from libraries, according to volunteer use, to the question regarding whether they had experienced a reduction in staffing in the past 5 years.

\section{Unionization in the libraries}

There is evidence of an association between the presence of a union in the library and the use of volunteers. When unions were present in the library, library volunteers were less likely to be used $\left(\chi^{2}(1, n=77)=4.77, p=0.029\right)$. A majority of all respondents, $53(69 \%)$, indicated that their libraries were not unionized. In libraries where volunteers are used, 38 (78\%) had no staff union. In comparison, $15(54 \%)$ libraries not using volunteers had no staff union. Table 4 summarizes the responses regarding unionization.

\section{Discussion}

This research found evidence of an association between a manager's belief in the adequacy of library staffing and the use of volunteers. Volunteers were more likely to be used by 
Table 2. Adequate staffing and volunteer use $(n=76)$.

\begin{tabular}{llll}
\hline $\begin{array}{l}\text { Staffing by paid } \\
\text { employees }\end{array}$ & $\begin{array}{l}\text { Using } \\
\text { volunteers }\end{array}$ & $\begin{array}{l}\text { Not currently } \\
\text { using volunteers }\end{array}$ & Total \\
\hline Adequate & $16(50.0)$ & $16(50.0)$ & $32(100)$ \\
Inadequate & $32(72.7)$ & $12(27.3)$ & $44(100)$ \\
Total & $48(63.2)$ & $28(36.8)$ & $76(100)$ \\
\hline
\end{tabular}

Note: The values in parentheses represent the percentage of libraries within each response to the question of whether there was adequate staffing with paid employees.

Table 3. Reduction of library staffing within the past 5 years and volunteer use $(n=75)$.

\begin{tabular}{llll}
\hline Staffing complement & $\begin{array}{l}\text { Using } \\
\text { volunteers }\end{array}$ & $\begin{array}{l}\text { Not currently } \\
\text { using volunteers }\end{array}$ & Total \\
\hline Reduction of staff & $13(17.3)$ & $10(13.3)$ & $23(30.6)$ \\
No reduction of staff & $34(45.3)$ & $18(24.0)$ & $52(69.3)$ \\
Total & $47(62.6)$ & $28(37.3)$ & $76(100)$ \\
\hline
\end{tabular}

Note: The values in parentheses represent the percentage of libraries within each response to the question of whether the library had experienced a reduction in staffing.

managers who did not believe they were adequately staffed. Contrary to the Ontario Hospital Association's position that states, "especially in times of severe economic constraint, that facilities prevent the perception that volunteers are being used to cover a staff shortfall" [7], our findings revealed that volunteers are being used to enhance the staffing levels in Ontario hospital libraries. Ontario hospital library managers who believe they are understaffed appear to be coping by enhancing the staffing in their libraries through the use of volunteers. The literature suggests that paid positions in libraries are often established because volunteers help to alert management that the work being performed is important and therefore should be paid. These notions were not supported by the findings in this research. No hospital library managers reported that the use of volunteers resulted in an increase to the library's staffing complement. This research found an association between the presence of a union in the library and the use of volunteers. When unions were present in the library, volunteers were less likely to be used.

Despite widespread volunteer use, when asked, hospital library managers were unaware of how library staff felt regarding volunteers and were unsure whether volunteer use made it easier for management to reduce staffing in the library. Managers acknowledged that although volunteers help to lessen the heavy workload in the library, volunteer assistance is perceived as a drawback because managers believed volunteers made it more difficult to justify the need for additional paid staff. Overall, volunteers were generally perceived as a disadvantage to maintaining and increasing staffing levels in the library, but they were appreciated for the help they provide with a heavy workload.

There are three options that Ontario hospital library managers may consider to address the issue of inadequate staffing.

(1) The current recommended staffing standards for Canadian health sciences libraries need to be prescriptive rather than descriptive. Staffing standards require strong recommendations regarding volunteer policy. Procedures
Table 4. Unionization in libraries $(n=77)$.

\begin{tabular}{llll}
\hline Unionization & $\begin{array}{l}\text { Using } \\
\text { volunteers }\end{array}$ & $\begin{array}{l}\text { Not currently } \\
\text { using volunteers }\end{array}$ & Total \\
\hline Yes & $11(14.2)$ & $13(16.8)$ & $24(31.1)$ \\
No & $38(49.3)$ & $15(19.4)$ & $53(68.8)$ \\
Total & $49(63.6)$ & $28(36.4)$ & $77(100)$ \\
\hline
\end{tabular}

Note: The values in parentheses represent the percentage of libraries within each response to the question of whether there is a union present in the library.

also need to be established to act as a check to ensure volunteers are not performing the duties of potential paid staff. One strategy that hospital library managers could adopt is to write job descriptions for volunteer library positions. These position descriptions could then be scrutinized by the union in the hospital that represents clerical staff to ensure that volunteers are not being asked to perform tasks that are part of a union's bargaining unit. The union could join with the library manager and together they could advocate to hospital administration for additional paid staff.

(2) Health sciences librarians could consider advocacy, lobbying, and networking with other components of the health care system to ensure hospital libraries continue to exist and are staffed with appropriate personnel. The problem of not having enforceable standards for hospital library staffing has prompted some health sciences library groups to take action. Montana librarians successfully incorporated health sciences libraries into the state-wide health care resource management plan developed under 1993 state law. The Montana Task Force for Biomedical Information was formed with funds from the National Network of Libraries of Medicine - Pacific Northwest Region and the Montana Area Health Education Center. The Task Force reviewed findings from national studies and trends in current state developments and deficiencies. The report was presented to the governor and state legislators in the context of costcontainment measures being considered in the state's health care reform bill. Montana law now provides that "it is further the policy of the state of Montana that the health care system should... facilitate universal access to current health sciences information", and "The management plan must include... identification of the current supply and distribution of... health sciences library resources and services" [8].

(3) Managers could formalize human resources planning in their libraries. Hospital libraries cannot deliver effective service without adequate and competent personnel. If the hospital library hopes to provide the best services to its clientele, it needs to calculate the required human resources to ensure its goal is achieved. Human resources planning in the typical hospital library is not a routine activity but an unrecognized, implicit process. Planning, in its widest sense, is deliberate direction, by persons in charge of large resources, of an activity towards chosen ends [9]. Human resources planning aims to ensure the efficient use of people. According to one author, it is concerned with making sure that the right number of workers is in the right place at the right time; it is also 
concerned with ensuring that the workers have the appropriate range of skills and expertise [10]. Human resources planning includes an evaluation of existing resources, an assessment of staffing requirements to achieve service objectives and outputs, and decisions about measures required to ensure that necessary resources are available when they are needed. It has been suggested [11] that a human resources plan needs to identify the following:

1. Projected increases in new and current activities

2. Activities projected to be eliminated

3. External constraints on optimum departmental performance

4. Staffing recommendations for the following scenarios:

a. No staff increases in the interim and long range period

b. Possibility of staff increases in the interim and long-range period

Hospital library managers need to formalize their human resources planning and receive direction from hospital authorities to identify the criteria used in the particular hospital to determine when increases to the staffing complement are warranted.

\section{Conclusions}

Research into best practices for volunteer use facilitates the creation of policies and procedures to aid hospital library managers in optimizing their use of volunteers. Policies surrounding volunteer use would provide direction and consistency in daily services and operation. Policies would also ensure that library volunteers and staff are treated fairly and consistently. These policies need to be strong and enforceable with regard to the activities of volunteers in libraries and must have the support of hospital administration. It is not sufficient to adopt a policy that proposes that volunteers should not be used as a substitute for paid staff or engage in activities that are essential to the library's operation. Hall and Love described the volunteer policy in force at the Kingston Frontenac Public Library [12]. The Kingston Frontenac policy takes into account the concerns of unions regarding volunteers, and all volunteer projects are reviewed and approved by a joint union-management committee. This could serve as a model for a hospital library.

There is a role for volunteers in hospital libraries, but it is one that needs to be clearly defined and continuously monitored. Library staff who turn to volunteers for help with heavy workloads need to be willing to devote the time necessary for their training and management. Volunteers should not be viewed as a quick fix or as a long-term solution to a library's understaffing problem. Instead, hospital library managers should focus their attention and energy on devising a realistic human resources plan for the library that is achievable and has the support of hospital administration. Otherwise, as our title suggests, hospital libraries in the future may find fewer library staff and more volunteers responsible for the delivery of library services.

\section{Acknowledgements}

Funding for this research was provided through a Chapter Initiative Grant from the Canadian Health Libraries Association / Association des bibliothèques de la santé du Canada.

\section{References}

1. American Library Association. Guidelines for using volunteers in libraries. Am Libr. 1971;2(4):407-8.

2. Library Association of Great Britain. LA policy on unpaid volunteers. Libr Assoc Rec. 1982;84(2):72.

3. Canadian Health Libraries Association / Association des bibliothèques de la santé du Canada (CHLA / ABSC) Task Force on Standards for Library \& Information Services in Canadian Healthcare Facilities. Standards for library \& information services in Canadian healthcare facilities. Toronto: CHLA / ABSC; 1995

4. Canadian Council on Health Services Accreditation (CCHSA). Standards for acute care organizations: a client-centered focus. Ottawa: CCHSA; 1995.

5. Dillman DA. Mail and telephone surveys: the Total Design Method. New York: John Wiley \& Sons; 1978.

6. Salant P, Dillman DA. How to conduct your own survey. New York: John Wiley \& Sons; 1994.

7. Ontario Hospital Association (OHA). Guidelines for volunteer involvement in health care facilities. Don Mills, ON: OHA; 1991.

8. Holt TM. From task-force to statute: establishing health sciences libraries in state law as a component of the health care system. Bull Med Libr Assoc. 1995;83(4):431-5.

9. Mittra A. Planning for manpower development in library \& information centers in India. Proceedings of the Seventeenth All India Conference of IASLIC; 1989 Dec 27-30; Jaipur, India. Calcutta, India: Indian Association of Special Libraries and Information Centres (IASLIC); 1989. p. 17-23.

10. Moore N. Manpower planning in libraries. London: Library Association; 1980.

11. Dewey BI. A practical methodology for the study of job components and staffing needs. College and Research Libraries. 1990;51(2):107-12.

12. Hall A, Love B. Library volunteers in a unionized environment. Access: the Official Publication of the Ontario Library Association. 2003;9(2):24-7. 